\title{
Psychological Resilience in Olympic Medal-Winning Coaches: A Longitudinal Qualitative Study
}

\author{
Mustafa Sarkar and Nathan K. Hilton \\ Nottingham Trent University
}

\begin{abstract}
Although there is burgeoning research on resilience in elite athletes, there has been no empirical investigation of resilience in elite coaches. The purpose of this study was to explore psychological resilience in world-class coaches and how they develop resilience in athletes. A longitudinal qualitative design was adopted due to the dynamic and temporal nature of resilience. Five Olympic medal-winning coaches (four males and one female) were interviewed twice over a 12-month swimming season. Reflexive thematic analysis was employed to analyze the data. Findings revealed 14 higher order themes, which were categorized into the following three general dimensions: coach stressors (managing the Olympic environment, preparation for major events, coach personal well-being, directing an organization); coach protective factors (progressive coaching, coaching support network, maintaining work/life balance, secure working environment, durable motivation, effective decision making); and enhancing resilience in athletes (developing a strong coach-athlete relationship, creating a facilitative environment, developing a resilience process, athlete individual factors). The results are presented to demonstrate the interplay between coach stressors and protective factors over time, which offers an original and significant contribution to the resilience literature by providing a unique insight into the dynamic and temporal nature of resilience in Olympic medal-winning coaches.
\end{abstract}

Keywords: elite sport, high-performance coaching, longitudinal qualitative design, protective factors, stressors

Over the last three decades or so, psychological resilience has been defined and conceptualized by many researchers (Fletcher \& Sarkar 2013), with a general consensus that resilience relates to positive adaptation despite the presence of risk or adversity (Fletcher \& Sarkar 2013; Luthar, Cicchetti, \& Becker 2000). Most recently, psychological resilience has been defined as "the role of mental processes and behavior in promoting personal assets and protecting an individual from the potential negative effect of stressors" (Fletcher \& Sarkar, 2012, p. 675, 2013, p. 16). This definition extends previous conceptual work in this area in a number of ways. First, the focus on psychological resilience delimits the scope of the description, by definition, to "mental processes and behavior" and excludes other types of resilience such as physical, molecular, and structural resilience. Second, this definition encapsulates aspects of both trait and process conceptualizations of resilience (Fletcher \& Sarkar, 2012, 2013). Third, the emphasis is placed on the more neutral term "stressor" rather than the negative value-laden term "adversity" (Fletcher \& Sarkar, 2013). Fourth, the focus is on "promoting personal assets and protecting an individual from the potential negative effect of stressors" rather than positive adaptation per se because resilience generally refers to the ability of individuals to maintain normal levels of functioning rather than the restoration or enhancement of functioning (Bonanno, 2004).

Within the sport psychology literature, over the past couple of decades or so, researchers have unearthed a wide range of stressors encountered by sport performers. Collectively, the stressors identified in these studies have been associated with competitive

The authors are with the Department of Sport Science, School of Science and Technology, Nottingham Trent University, Nottingham, United Kingdom. Sarkar (mustafa.sarkar@ntu.ac.uk) is corresponding author. performance, the sport organization within which athletes operate, and personal "nonsporting" life events (Sarkar \& Fletcher, 2014). Due to the numerous and variety of stressors encountered by sport performers, researchers have investigated psychological resilience in athletes to understand why some individuals are able to withstand-or even thrive on-the stressors they experience (Bryan, O'Shea, \& MacIntyre, 2019; Galli \& Gonzalez, 2015).

The earliest studies in a sporting context largely centered on resilience in relation to performance failure (Martin-Krumm, Sarrazin, Peterson, \& Famose, 2003; Mummery, Schofield, \& Perry, 2004; Seligman, Nolen-Hoeksema, Thornton, \& Thornton, 1990). To illustrate, Martin-Krumm et al. (2003) examined the relationship between explanatory style and resilience in a group of recreational basketball players using an experimental approach. Following failure feedback in a dribbling task, optimistic participants were found to be more confident, to be less anxious, and to perform better than pessimistic participants. Adopting a more ecologically valid approach, Mummery et al. (2004) explored the impact of three protective factors (self-concept, social support, and coping style) against three performance-related outcomes (i.e., initially successful performance, resilient performance involving an initial failure followed by subsequent success, and nonresilient performance involving an initial failure followed by subsequent failure) in a National Swimming Championship. Findings revealed that resilient performers had higher self-perceptions of physical endurance but lower perceptions of social support than the other two groups. Moreover, the initially successful performers had higher perceptions of peaking under pressure and coping with adversity than the other groups. Although early work in this area provided an initial insight into resilience in sport performers, it is worth noting that the research focused on a limited number of psychological characteristics (optimistic explanatory style, self-concept, social support, and coping style) that precluded 
participants from providing a broader insight into the trait and process elements of resilience.

Taking a more holistic approach to resilience inquiry, Galli and Vealey (2008) interviewed college and professional athletes about their perceptions and experiences of resilience using Richardson (2002) and Richardson, Neiger, Jensen, and Kumpfer (1990) resiliency model as a guiding theoretical framework. Five general dimensions emerged that described the resilience experience of the athletes. These dimensions included breadth and duration, agitation, sociocultural influences, personal resources, and positive outcomes. A drawback of the study was that it was driven by Richardson et al.'s model, which is a particular concern since it has various limitations, including the linear stage framework evident within its structure, the absence of meta-cognitive and meta-emotive processes, and its bias toward coping-oriented processes (Fletcher \& Sarkar, 2013).

In an attempt to address the limitations of Galli and Vealey's (2008) work, researchers (Fletcher \& Sarkar, 2012; White \& Bennie, 2015) have employed inductive qualitative designs to explore resilience free from the constraints of a preconceived model. To illustrate, Fletcher and Sarkar (2012) developed a grounded theory of psychological resilience in Olympic champions. They interviewed 12 Olympic gold medalists to explore and explain the relationship between psychological resilience and optimal sport performance. The findings revealed that numerous psychological factors (relating to a positive personality, motivation, confidence, focus, and perceived social support) protected the world's best athletes from the potential negative effect of stressors by influencing their challenge appraisal and meta-cognitions. These constructive cognitive reactions promoted facilitative responses that led to the realization of optimal sport performance. Interestingly, it was observed that coaches played an important role in athletes' resilience and thus, Fletcher and Sarkar (2012) noted that "future research . . . should consider the perception of significant others surrounding these athletes, such as coaches" (p. 676).

In one of the few sport-related resilience studies to date to sample coaches, White and Bennie (2015) recently investigated gymnast and coach perceptions about the development of resilience through gymnastics participation. Underpinned by a qualitative design, 22 female gymnasts and seven gymnastic coaches participated in semi-structured interviews. Data analysis revealed that aspects of the gymnastics environment created stress and exposed gymnasts to many challenges in training and competition. Features of the sport environment, such as interpersonal relationships and positive coach behaviors, supported gymnasts through these challenges and encouraged them to overcome failure. Gymnastics participation was perceived to develop resilience, as well as life skills, self-efficacy, and self-esteem. Importantly, White and Bennie (2015) noted that "the community gymnastics sample meant that the findings might not to wholly applicable to . . . athletes from other sports. As such, future research needs to be conducted in diverse sporting contexts" (p. 390).

Although there is burgeoning research on psychological resilience in elite athletes (Bryan et al., 2019; Galli \& Gonzalez, 2015), to date, there has been no empirical investigation of resilience in elite coaches. Indeed, when discussing implications for future research, Sarkar and Fletcher (2016) noted:

Since elite sport coaches operate within complex, everchanging environments that impose many pressures on them (see, for a review, Fletcher \& Scott, 2010), future research should examine resilience in elite coaches. Specifically, due to the exploratory nature of this emerging area of inquiry, researchers should initially ... strive to understand... resilience amongst coaches and how this impacts their ability to foster resilience in their athletes. (pp. 241-242)

The purpose of this study is, therefore, to explore psychological resilience in world-class coaches and how they develop resilience in athletes. In order to meet this objective, a longitudinal qualitative design will be adopted due to the dynamic and temporal nature of resilience (Egeland, Carlson, \& Sroufe, 1993; Luthar et al., 2000). It is hoped that this study will offer an original and significant contribution to the resilience literature by providing a unique insight into how resilience unfolds over time in Olympic medal-winning swimming coaches.

\section{Method}

\section{Research Design}

This study was deemed best suited to qualitative methods in view of the scant knowledge of psychological resilience in elite coaches. As Bonanno (2012) asserted, "qualitative studies of putatively resilient samples ... provide a valuable source of new ideas and information, especially in populations that have not yet benefitted from systematic study" (p. 755). Qualitative methods are also particularly appropriate for better understanding the complexity of psychosocial phenomena (Silverman, 2006), such as resilience in the context of elite sport coaching. Indeed, qualitative researchers in this area have stated that such an approach can account for the specific context in which resilience is manifested (Ungar, 2003). In terms of an underpinning philosophical orientation to this study, we develop knowledge through a process of interpretation (i.e., epistemologically interpretivist) and believe in retaining a balanced outlook (i.e., ontologically realist).

A longitudinal qualitative design (Hermanowicz, 2013) was employed to better understand how resilience unfolds over time (Egeland et al., 1993; Luthar et al., 2000). Specifically, coaches' resilience was explored via interviews at two specific time points (September and April) over a 12-month swimming season. These specific time points were chosen since they are significant within the swimming coaching yearly calendar. These time points were September 2016, post-Olympic season, and just prior to World Championship selection trials in April 2017. It was hoped that conducting interviews over these time points would help to illustrate the dynamic and temporal nature of resilience involving constant anticipation and fine-tuning during adverse conditions. Methodologically, this extends the extant sport resilience literature, which has typically employed single interviews to explore resilience (Fletcher \& Sarkar, 2012; Galli \& Vealey, 2008; White \& Bennie, 2015). Indeed, in their study with athletes, Galli and Vealey (2008) noted that "a major limitation of this study was the use of single interviews ... . Single interviews may not provide the depth of data necessary to adequately draw conclusions regarding a phenomenon. Future qualitative studies of resilience . . . should adopt a longitudinal interview schedule" (p. 330). Similarly, in their study with athletes and coaches, White and Bennie (2015) mentioned that "another limitation was the use of a single interview with each participant. This method did not take into account the dynamic nature of resilience, which may be captured through multiple interviews with the same person. Future researchers should create longitudinal studies on resilience" (p. 390). 


\section{Participants}

The participants were five elite swimming coaches (four males and one female) who ranged in age from 34 to 65 years $(M=51.2, S D=$ 11.23). The participants had coached Olympic-level swimmers for between 4 and 30 years $(M=19.2, S D=9.85)$. Participants had attended between one and six Olympic games as a coach $(M=3.6$, $S D=1.85)$ and had directly coached between one and five Olympic medalists $(M=2.4, S D=1.5)$. Two of the participants had coached Olympic champions, and the other three coached Olympic silver medalists. To the best of our knowledge, these were the only five active swimming coaches to coach Olympic medalists in Great Britain at the time of the study. All coaches had worked as Head Coaches for the National Governing Body at some point during their careers. At the time of the study, two were Head Coaches for the National Governing Body, and three were Head Coaches in a club-based setting. Participants own swimming levels ranged from Midland District Finalist through to Olympic Finalist levels, and all coaches were based in the United Kingdom.

\section{Procedure and Data Collection}

Following institutional ethical approval at Nottingham Trent University, a database of potential participants was identified using the "Hall of Fame" information available from the British Swim Coaches' Association, and contact details for each potential participant were acquired. Potential participants were subsequently contacted by email. This correspondence informed them of the purpose of the study, what it entailed for participants, and invited them to participate in two interviews over a 12-month swimming season. All of the potential participants agreed to the invitation and were contacted to arrange a mutually convenient time and location to meet. All of the participants provided informed consent before the start of data collection.

Semi-structured interviews were conducted face to face by the second author. Due to the longitudinal nature of the study (Hermanowicz, 2013), two interview guides were developed. Interview guides were developed in advance to help the interviewer explicitly think about what might be covered in the interview to facilitative the interview process, ultimately to better understand the participants' subjective experiences (Patton, 1990, 2002). The interview guides did not represent a rigid document, but rather a flexible set of evolutionary questions depending on the direction taken by the participant during the course of the discussion (Silverman, 2006). All of the interviews involved asking a series of open-ended questions and adopted a conversational tone.

Interview 1. The first semi-structured interview guide was constructed with five sections focusing on background information, coaching pressures/setbacks/adversities, coaches' personal resilience, developing resilience in athletes, and practical suggestions for aspiring elite coaches. Specifically, the interview began by asking participants about their career backgrounds (e.g., "I was wondering if you could tell me about your coaching career to date and your proudest moment as a coach?"). The coaches were then asked about pressures/setbacks/adversities they had faced (e.g., "Could you describe sport-related pressures that you have experienced in the last few months?"). The focus of the interviews then shifted toward the participants' perceptions of the qualities they felt had enabled them to withstand the stressors of elite sport coaching (e.g., "What characteristics do you think helped you to withstand the pressures you have encountered in the last few months?") and toward coaches' experiences of developing resilience in athletes (e.g., "Can you explain what type of environment you have created in the last few months to help athletes deal with pressure?"). Finally, the guide concluded with several questions designed to elicit advice for aspiring elite coaches (e.g., "How would you advise aspiring elite coaches to view and deal with pressure in relation to their coaching?").

Interview 2. In line with the purpose of the present study, the second semi-structured interview guide focused on three of the five sections in the first interview, namely coaching pressures/setbacks/ adversities, coaches' personal resilience, and developing resilience in athletes. Hermanowicz (2013) noted that there are two means to structure interview protocols in longitudinal qualitative research, either posing the same questions on the same themes or posing different questions on selected same and newly emergent themes. The former approach was adopted in the present study since "LQIs [longitudinal qualitative interviews] designed in advance lend themselves to protocols containing identical questions posed to respondents at different times in order to assess change [over time]" (p. 198). To supplement this process, clarification (e.g., "I'm not sure exactly what you meant, could you please go over that again?"), elaboration (e.g., "Could you please explain that in more detail?"), and general (e.g., "What effect did that have?") probes were used to further explore the surfacing data (Patton, 2002) and to build on data collected during the first interview.

\section{Data Analysis}

The interviews, which ranged in duration from 42 to $86 \mathrm{~min}(M=$ 58.7, $S D=17.7)$, were digitally recorded in their entirety and transcribed verbatim, yielding 210 pages of single-spaced text. The transcripts were analyzed using the reflexive thematic analysis procedures outlined by Braun and Clarke (Braun \& Clarke, 2006, 2016; Braun, Clarke, \& Weate, 2016; Clarke \& Braun, 2014). First, to become familiar with the data, the transcripts were read and reread, and brief notes were recorded to create some preliminary ideas for the next phase of the analysis. Second, codes of interest were generated by extracting and collating pertinent excerpts of the data. Third, all of the codes were organized into potential themes that reflected the content and meaning of the data. Fourth, the themes were reviewed and refined in relation to the generated codes and the entire data set. Fifth, the themes were labeled and defined by attempting to capture the essence of the data it contained. Sixth, compelling extracts were selected to relate the analysis back to the research question. Throughout this process, in line with and due to the longitudinal nature of the study (Hermanowicz, 2013), the approach of constant comparison was used (Charmaz 1990; Glaser \& Strauss 1967; Strauss \& Corbin 1994). Specifically, using an inductive and deductive approach, themes were elaborated or modified through further data collection and analysis (i.e., from the second interview). Furthermore, to explore change over time, following Saldana's (2003) recommendations for longitudinal qualitative research, a variety of conceptual and thematic questions were employed to help situate data analysis (e.g., What remains constant or consistent with time? What is idiosyncratic through time? Which changes interrelate through time? What are participant rhythms through time?).

\section{Methodological Quality and Rigor}

Although some scholars have opposed the development of unvarying universal standards for qualitative research (Sparkes \& Smith, 2009; Smith \& McGannon, 2018), it is important to assess the 
quality of a study using evaluative criteria most appropriate for the research question and generated data (Roulston, 2010). Judging the quality of the findings was realized in this study through five main criteria or approaches (Smith \& McGannon, 2018; Tracy, 2010). First, to achieve rich rigor, the study used appropriate and wellestablished data collection and analysis procedures and provided abundant rich data from significant and distinctive participants. Second, in accordance with the researchers' ontologically realist beliefs, sincerity was realized through reflexivity about the potential subjective biases and transparency associated with the methods. Specifically, the second author (director of coaching at a local swimming club) maintained a field log throughout all phases of data collection and analysis, and a clear account of the research process was recorded and reported to ensure that the reader is able to understand how the study was conducted. Third, to evaluate the credibility of the analysis, a "critical friend" was adopted to enable the researchers to think critically about the thematic structure being developed. This critical friend was an academic colleague who had approximately 8 years of experience as a qualitative researcher and a competing and coaching background in elite swimming. Importantly, rather than being adopted to achieve agreement or to reach consensus, a critical friend was used to encourage alternative explanations and interpretations of the data (Smith \& McGannon, 2018). Fourth, resonance was achieved through the transferability of the findings, specifically by reporting direct quotations from participants, providing rich description and writing accessibly (Ungar, 2003). Finally, the research considered both procedural and relational ethics (Tracy, 2010). Specifically, the American Psychological Association's (2010) Ethical Compliance Checklist was completed, and consistent with the researchers' epistemologically interpretivist beliefs, the mutual connectedness between the researcher and participant was valued.

\section{Results}

The results derived from data analysis procedures represent the collated interview responses from all five Olympic medal-winning coaches. The interview data yielded 14 higher order themes, which were categorized into the following three general dimensions: coach stressors, coach protective factors, and enhancing resilience in athletes (see Table 1). Drawing directly from the experiences of the participants across the two interviews, each general dimension will be illustrated by direct quotations from the transcripts, with the aim of providing an insight into how resilience unfolded over a 12-month swimming season in world-class coaches.

\section{Coach Stressors}

Four higher order themes were identified in this dimension: managing the Olympic environment, preparation for major events, coach personal well-being, and directing an organization.

Managing the Olympic environment. This higher order theme included 14 initial data codes, which were grouped into two lower order themes (failure as an athlete at the Olympic Games or trials and failure/stress while at the Olympic Games or trials). Managing the Olympic environment described the pressures associated with qualifying for, or competing at, the Olympic Games, as described in the following quote from Coach 2:

But certainly it's a bit more stressful going to trials then going to the Olympic Games. The Olympic Games I felt relaxed, I felt I was at ease. I felt I belonged there and loved it. And I think my swimmers got that from me as well. (Interview 1, September 2016, Coach 2)

When asked to describe the sport-related pressures they had experienced in the last few months, in the second interview, Coach 2 provided a different response, focusing on the stressors associated with working at a national center/governing body, highlighting the need for different protective factors during different periods in time:

I mean it's hard to get my head round anything, with the big restructure. It really is. I mean, if I'm honest, you know how I said part of it is like, yeah, but it is all about the Olympics and we have done really well and, maybe, I'm not as hungry in that as I should be, even myself. I had a conversation with some of them and even me was, like, well we'll see how it goes and I would always be, like, the Worlds are coming up, but I'm a bit like, yeah, it is about the Olympics and there's four years in between and it is a Worlds, but it's not the Olympics. So it's part of it, for the first time-and I'm not sure if it's a good thing-I'm actually thinking, well, yeah, it is what it is. But I don't want to be like that. I want to be really hungry and ready for the next one and I think I'm getting there. I don't think I'm there yet, but I think I'm getting there. But, like I say, you can tell that everything you're saying I've gone through such a big change and it was huge and it's even hard to relate anything past that. (Interview 2, April 2017, Coach 2)

Preparation for major events. This higher order theme consisted of 15 initial data codes, which were grouped into two lower order themes (managing the training process and demands of the competition process). This higher order theme illustrated the pressures and complexity associated with the long-term preparation for major events, as described by Coach 3 in the following quote, when discussing the preparation/lead-up to the Olympic Games:

If you look at a coaching point of view, a good example if you look at [Olympian's name], at least she got [an illness]. She's got nearly a year out. She went to the World Championships. I thought she was a stitched on medal in [year of competition].

\section{Table 1 Three General Dimensions and 14 Higher Order Themes}

\begin{tabular}{ll}
\hline General dimension & Higher order themes \\
\hline Coach stressors & Managing the Olympic environment \\
& Preparation for major events \\
& Coach personal well-being \\
& Directing an organization \\
Coach protective factors & Progressive coaching \\
& Coaching support network \\
& Maintaining work/life balance \\
& Secure working environment \\
& Durable motivation \\
& Effective decision making \\
& Developing a strong coach-athlete \\
relationship \\
Enhancing resilience in \\
athletes & Creating a facilitative environment \\
& Developing a resilience process \\
& Athlete individual factors \\
\hline
\end{tabular}


Swam like a brick. She mispaced it, got it all wrong. So that was a major disappointment, but then 12 months later she went to the Olympics and won two gold medals. It just shows you, you have just got to handle it. (Interview 1, September 2016, Coach 3)

Coach personal well-being. This higher order theme included 19 initial data codes, which were grouped into two lower order themes (coaches' personal life and demands of a coaching career). This higher order theme focused on coaches' own personal lives and the pressures associated with elite coaching. The following quotefrom Coach 1 specifically relates to the coach's inability to switch off:

I think my greatest challenge has been and still is - my greatest challenge is confusing my life and my work life as the two being completely one. And I'm a lot better at it than I was, but my moods would depend on how well my swimmers have been going or, you know, it was very much-my mood was very much related to how my work was going, which wasn't healthy. It was okay. It was livable. It was just not-It was just not a sustainable way to live, you know. (Interview 1, September 2016, Coach 1)

When probed on his well-being in the second interview, it was evident that Coach 1's perceptions of pressure changed significantly in comparison to his first interview, illustrating the dynamic nature of resilience:

Personally, phew, split my head open. Last 6 months, just moving house maybe would be a big deal. That's just not happened yet but it's about to. I've got a bit of a heart tremor, is that stressing me out, no it's not really stressing me out. It's not stressing me out because there's nothing I can do about it. (Interview 2, April 2017, Coach 1)

Directing an organization. This higher order theme included 33 initial data codes, which were grouped into three lower order themes (working in a club environment, working at a national center/governing body, and managing the daily environment). This higher order theme encapsulated the pressures of being a senior manager/coach within an elite coach setting, as expressed by Coach 3 in the following quote:

There were big decisions to make, there were big calls to make, but I don't find that any more stressful than some of the decisions you make that affect people's jobs and livelihoods. I mean, part of my role now you know? I have to make some hard calls not just with athletes, but with-with staff. You know so none of those decisions are easy, you know whether it's-whether it's stopping someone's funding. Whether it's changing something at a national centre whether it's not giving the club program money. Whether it's you know sitting there with an athlete, and saying, "Not investible anymore." So, there's - there's lots of difficult decisions to make day in and day out. But I think you-you know it takes certain mindset to handle and deal with that. (Interview 1, September 2016, Coach 3)

\section{Coach Protective Factors}

Coach protective factors refer to the characteristics or qualities that protected coaches from the potential negative consequences of the stressors they encountered. Six higher order themes were identified in this dimension: progressive coaching, coaching support network, maintaining work/life balance, secure working environment, durable motivation, and effective decision making.

Progressive coaching. This higher order theme included 25 initial data codes, which were grouped into two lower order themes (coaching behaviors and personality traits). This higher order theme recognized coaches' ability to view pressure/setbacks/adversity in a positive manner coupled with numerous positive personality traits (e.g., optimism, proactivity, conscientious). This is highlighted in the following quote from Coach 4 :

Yeah, just trying to make progress and listen and evaluate things and just, I think it's all about progress to me, resilience, how quickly you can turn around disappointment, how quickly you can succeed any better through this challenging situation and who you become amidst the challenge and that's what I try to do is, every challenge that we do, I either try to become better, a better operator or get a better result. (Interview 1, September 2016, Coach 4)

Coaching support network. This higher order theme included 12 initial data codes. The coaching support network described the coaches' perceived and received social support from a variety of sources and is reflected in the following quote from Coach 5:

So I haven't really had a mentor, but what I've had is numerous people that I would like to sit down, and discuss it with. Like when I was at [name of town] [sport scientist name], whenhim and I, every session, and that's ten sessions a week. But year in year out, [sport scientist name] and I sat down at the end of each session. And say, "How did that go?" What's the next-now? That's not a mentorship. What that is, is simply understanding did it go as well as I thought it went? What's your opinion, what's your opinion of what's coming next, and whether you take that advice or not is up to you-your choice. (Interview 1, September 2016, Coach 5)

In contrast to the first interview, when questioned on similar topics in the second interview, Coach 5 recognized the importance of having a formal mentor, but, similar to the first interview, the coach acknowledged having a coaching support network as being an important factor for protection against the potential negative effect of stressors:

I think the support mechanism; you need somebody to be able to sound off to. The support mechanism is usually somebody listening to you, somebody giving you advice, and the mentor situation is so important. You say, "well, look, I did this, and it didn't work?" Then your mentor says, “at what degrees didn't it work?" You might be on the right track, just not doing enough of it. So, everybody needs somebody to sound off to, because coaches live in isolation, and it's the coach's responsibility, in my opinion, to actually find somebody that will listen to him, can sound off to, and not make a value judgement, but help in judgement. (Interview 2, April 2016, Coach 5)

Maintaining work/life balance. This higher order theme included 14 initial data codes, which were grouped into two lower order themes (outside interests/hobbies and controlling the process). This higher order theme recognized the coaches' ability to maintain a healthy balance between work and their personal lives via engaging in external activities. This is highlighted in the following quote from Coach 1:

Yeah. I do quite a lot of voluntary work; four or five times a week sometimes. I keep fit. That's a really big part of my day. 
Yeah, I am able to go out on walk on-I'm sort of able to do stuff other then maybe the stuff that I used to do. And to switch off, I can jump in to camper van if I want to go away for the weekend. I can, you know, just traveling and driving and camping out, eating, cooking. I find it very easy to switch off from the pool nowadays. It's really—almost too easy. Sometimes I think, you know, sometimes I think, "Am I losing it?" I am able to walk out of the pool and no matter what's happened-this is not true; I am not telling a lie. Most of the time I can just leave everything where it was whether it was a good session or whether it was a bad session, whereas in the past, I would come out the pool and I would be punching the air or going, "Yeah," and calling my missus up and I'll be saying to her, "Yeah, yeah." I'd be so up, you know. Or if it was bad, I would come in and be saying he was rubbish and argghh. I just don't do that anymore. (Interview 1, September 2016, Coach 1)

When probed around maintaining work/life balance in the second interview, Coach 1 provided a different process for withstanding stressors (controlling the process) than detailed in the first interview (outside interests/hobbies), highlighting the need to maintain balance in different ways depending on the time point of the swimming season:

My key psychological factor or trick or tool is my daily routine. The daily routine is fool proof. It should, if done correctly, leave you in a good place every day. Look after yourself, healthily, be healthy I should say, do the right thing. Every morning's the same deal with me. I get up, I drink water, I stretch, I write a list. On that list is the things I have to do that day, the things that I would like to do that day and my goal, what am I doing. All those things on a piece of paper and I have things that I will not do that day, for me that's really important . .. and at night I review my day, religiously. I go through my list and if I've not done anything that will carry over to tomorrow but I can throw that list away. By doing that I keep everything in the day. I try never to have any carry over. (Interview 2, April 2017, Coach 1)

Secure working environment. This higher order theme described a daily work environment that enabled coaches to work effectively under pressure while allowing them to deliver success at the highest level. It included 25 initial data codes, which were grouped into three lower order themes (confidence in the role, working effectively in the coaching environment, and controlling self-doubt). This higher order theme recognized coaches' confidence, their ability to work effectively, and controlling insecurities within the working environment. This is highlighted in the following quote from Coach 4 , where she discussed her positive perception of the work environment:

It's really difficult, like I say, at the minute because I just feel like I've faced all my adversities in the last three years in my current job, whereas I feel here I face no problem. When you're in world class sport I feel like nothing's a problem, it's a challenge. How do we find a way forward? So when you're in a club you're dealing with problems. You're dealing with kids that are self-harming. You're dealing with parents that are wanting to knock you out. You're dealing with councils that have got no idea or no care because they are in the same funding category. You're dealing with impossible situations all the time. Here it's not impossible. Everything is possible really. (Interview 2, April 2017, Coach 4)
Durable motivation. This higher order theme included 25 initial data codes and described the coaches' ability to maintain motivation over extended periods of time to enable them to continuously develop themselves to ensure Olympic success was sustained. These codes were then organized into three lower order themes (intrinsic motivation, continual self-development, and extrinsic motivation). This higher order theme described how coaches managed to keep themselves continually motivated even when faced with pressure, setbacks, and adversity. The following quote from Coach 5 illustrates the personal drive and ambition associated with durable motivation:

Or is it a vocation. Now, with me it's always been vocation, always. But with some people it—it's nothing more than a job, and if you want to be successful it's-it's-it's whatever it takes. To get results. Whatever it takes. And if you're not prepared to do that than you're not going to get a-a result of the highest level in the world. (Interview 1, September 2016, Coach 5)

Effective decision making. This higher order theme included 13 initial data codes and no lower order themes. This theme described the coaches' ability to self-reflect, analyze, and continually make effective decisions when under pressure. This is highlighted in the following quote from Coach 3:

I think you learn from it. You know, how that I used to coach when I was 35 and then how I coach now. Totally different. I think that again that's a trait of more resilient coaches. Because some coaches-coached 30 years. But coached one year thirty times. Whereas, the more resilient coaches from any sport. Learn from the mistakes, and I've made thousands of mistakes don't worry about that, but I've tried not to make them twice. Certainly not the three times. (Interview 1, September 2016, Coach 3)

\section{Enhancing Resilience in Athletes}

Four higher order themes were identified in this dimension (developing a strong coach/athlete relationship, creating a facilitative environment, developing a resilience process, and athlete individual factors). Specifically, this general dimension described how coaches developed relationships with athletes, created a vibrant/positive environment, delivered training to facilitate resilience, and utilized factors that were individual to each athlete.

Creating a facilitative environment. This higher order theme described how coaches created a challenging and supportive environment that athletes could thrive in as both a person and a performer. In the following quote, Coach 3 discusses the importance of operating in an environment with clear and high expectations:

Well, it's my job in the last four months have been the Olympic Team. So, what we've done is we have-we have a series of behaviours you know? On the team now that I would tell you which we consider to be world class. So, how you conduct yourself, how you think, how you act, how you respond, how you prepare. How you debrief. Everything around the performance with those athletes, coach, support staff, leadership teams. Everything we behave in a certain way. I mean, we have about five or six basic pillars that underpin that, and it's everybody's responsibility to behave in that way. And if they see someone not behaving in that way too- to- toto police that. Yeah? So, that's the big difference now on the national team. (Interview 1, September 2016, Coach 3) 


\section{Discussion}

Utilizing a longitudinal qualitative interview design (Hermanowicz, 2013), this study explored psychological resilience in world-class coaches and how they developed resilience in athletes. The findings revealed 14 higher order themes, which were categorized into the following three general dimensions: coach stressors (managing the Olympic environment, preparation for major events, coach personal well-being, directing an organization); coach protective factors (progressive coaching, coaching support network, maintaining work/life balance, secure working environment, durable motivation, effective decision making); and enhancing resilience in athletes (developing a strong coach-athlete relationship, creating a facilitative environment, developing a resilience process, athlete individual factors).

\section{Coach Stressors}

Four higher order themes were identified in this general dimension, namely managing the Olympic environment, preparation for major events, coach personal well-being, and directing an organization. Although several authors have identified and explored the stressors associated with coaching and elite sport coaching, in particular (Fletcher \& Scott 2010; Frey, 2007; Olusoga, Butt, Hays, \& Maynard, 2009; Olusoga, Butt, Maynard, \& Hays, 2010; Olusoga, Maynard, Hays, \& Butt, 2012; Thelwell, Weston, Greenlees, \& Hutchings, 2008a, 2008b; Thelwell, Weston, \& Greenlees, 2010), none have examined these stressors over a longitudinal time period. Indeed, the current study found that additional stressors became apparent over time, especially during intense periods of prolonged pressure, such as selection trials or the Olympic Games itself. Thelwell et al. (2008b) categorized elite coach stressors into six general dimensions, which were balanced between performanceand organizational-related stressors. Olusoga et al. (2009) conducted further research into the stressors associated with world-class coaches. Specifically, they identified 10 higher order themes, which similarly found performance- and organizationalrelated stressors that coaches regularly experience. While these studies identified these particular pressures, they did not identify personal demands that are frequently encountered by coaches. Thus, the current study supported previous findings within these studies (Olusoga et al., 2009; Thelwell et al., 2008b) while also identifying new areas such as the higher order theme of coaches' personal well-being. Although personal stressors have been identified as a common demand encountered by athletes (Sarkar \& Fletcher, 2014), they have yet to be identified and explored in elite coaches. Thus, the current study extends previous observations by identifying an inability to maintain personal well-being as a pertinent stressor in world-class coaches.

\section{Coach Protective Factors}

Six higher order themes were identified in this general dimension, namely progressive coaching, coaching support network, maintaining work/life balance, secure working environment, durable motivation, and effective decision making. Although numerous factors that protect individuals from the potential negative effect of stressors have been investigated in athletes (Fletcher \& Sarkar, 2012; Galli \& Vealey, 2008), the current study is the first to explore and identify protective factors in (world-class) coaches.

The higher order theme of progressive coaching encompassed a wide range of coaching behaviors and personality traits, such as openness to learning, conscientiousness, optimism, and proactivity.
These findings support previous research with successful Olympic (Mallett \& Coulter, 2016) and serial winning coaches (Mallett \& Lara-Bercial, 2016). The higher order theme of the coaching support network recognizes the importance of social support as a crucial factor, which protects coaches from the potential negative effects of stressors. Interestingly, while perceived social support has been identified as an important factor underpinning resilience in elite athletes (Fletcher \& Sarkar, 2012), coaches interviewed in this study valued both perceived and received support when dealing with pressure, setbacks, and adversity. Maintaining work/life balance was considered to be an essential factor in buffering coaches from the stressors they experienced. Olusoga et al. (2010) recognized "distraction" as a theme in their research into stress and coping in world-class coaches. The current study extended this further and provided additional longitudinal insights into how maintaining work/life balance provides coaches with protection from stressors over time, with the need to maintain balance occurring in different ways (e.g., by having outside interests/hobbies vs. controlling the everyday coaching process) depending on the time point of the season.

Having a secure environment was identified as an important protective factor in Olympic medal-winning coaches. Specifically, the participants suggested that having confidence in their roles, working effectively in the coaching environment, and controlling self-doubt offered a secure working environment that, in turn, provided a platform to withstand stressors. This supports the notion of the "greenhouse effect" (Lara-Bercial \& Mallett, 2016), whereby key features of the environment (e.g., personnel, resources, schedules, relationships) and the motivational climate remain relatively stable so staff and athletes can concentrate on doing their jobs to the best of their ability under pressure. Durable motivation described the coaches' ability to have a continuous stable drive toward their goals, with minimal fluctuation, even when faced with pressure/ setbacks/adversity. Specifically, being driven by multiple intrinsic (e.g., searching for learning opportunities, exposure to challenging environments) and extrinsic (e.g., winning Olympic medals, being paid a fair salary) motives appeared to protect coaches from negative consequences. Finally, coaches believed that effective decision making was crucial for them to withstand pressure. This supports the study conducted by Mallett and Lara-Bercial (2016) that focused on serial winning coaches, with findings suggesting that the key skills for the coaches to succeed were effective communication, planning, and decision making, with particular reference made to serial winning coaches being able to "see the bigger picture" and make necessary decisions. To the best of the authors' knowledge, research into the role of effective decision making as a protective factor has not been fully examined yet in the sport resilience literature, and hence it could make for an interesting avenue for future investigation.

\section{Enhancing Resilience in Athletes}

This final general dimension had four higher order themes (developing a strong coach/athlete relationship, creating a facilitative environment, developing a resilience process, and athlete individual factors). The current study identified that world-class coaches develop a robust and collaborative relationship with their athletes when developing psychological resilience for long-term achievement. Research by Mallett and Lara-Bercial (2016) recognized that while collaborative coach-athlete relationships have been reported in elite sport (Hodge, Henry, \& Smith 2014), this style of leadership has not been frequently cited when considering successful 
performance under pressure at the world-class level. Coaches also identified that creating a facilitative environment enhanced the athletes' ability to withstand stressors. This supports the proposition by Fletcher and Sarkar (2016) that a high challenge-high support (facilitative) environment is optimal for developing resilience in performers (Sarkar, 2018), as well as supporting the research by Lara-Bercial and Mallett (2016), who noted that a challenging training environment with a certain level of stability and dependability was fundamental to sustained success. The current study has also provided further areas for consideration when attempting to facilitate a holistic and systematic approach to enhancing psychological resilience in athletes. Specifically, athlete individual factors were described as a key element in developing resilience, such as experiencing repeated failure and learning from adversity (Sarkar \& Fletcher, 2017a; Sarkar, Fletcher, \& Brown, 2015).

\section{Strengths and Limitations}

When interpreting the findings of an investigation of this kind, it is important to recognize some of the strengths and limitations. In our view, a major strength of this study is the makeup of the sample, specifically the supra-elite nature of the participants. Specifically, the coaches who participated in the interviews were Olympic medal-winning coaches who had substantial experience of positively adapting to pressure/setbacks/adversity at numerous points during their coaching careers. Indeed, it has been suggested that the study of significant samples (i.e., participants who are distinguished in some way) greatly enriches psychological science (Simonton, 1999). Due to the dynamic and temporal nature of resilience (Egeland et al., 1993; Luthar et al., 2000), another strength of this study, in our view, is the longitudinal qualitative interview design (Hermanowicz, 2013). The nature of this design enabled unique insights to be gleaned into how resilience unfolded over time. Specifically, it allowed for an examination of the dynamic nature of coaches' thoughts, feelings, and behaviors throughout the process of dealing with pressures/setbacks/adversities (Galli \& Vealey, 2008). Methodologically, this extends the extant sport resilience literature, which has typically employed single interviews to explore resilience (Fletcher \& Sarkar, 2012; Galli \& Vealey, 2008; White \& Bennie, 2015).

Notwithstanding these strengths, a potential drawback of the study is the limited characteristics of the sample in terms of sport, culture, and gender. Specifically, all coaches were solely from swimming, were all based in the United Kingdom, and were predominantly male. Furthermore, although the longitudinal qualitative interview design was considered a strength of a study, a potential limitation could be the limited period of investigation (i.e., two interviews over a 12-month season). Future researchers should explore resilience in Olympic coaches with multiple (i.e., three or four) interviews over a longer time period (e.g., a 4-year Olympic cycle) to better understand the dynamic and temporal nature of resilience.

\section{Future Research}

The findings reported here suggest that resilience in elite coaches is likely to be a fruitful avenue for researchers to explore. Here, we discuss three main areas that we believe will advance knowledge in this area. First, there is a need for more large-scale longitudinal studies (Bryan et al., 2019; Galli \& Gonzalez, 2015). Qualitative research involving multiple contact points and methods of data collection will further elucidate the process of resilience in coaches. In addition, quantitative research, using advanced statistical modeling techniques (e.g., structural equation modeling, latent growth mixture modeling), will allow researchers to explore resilience pathways and trajectories in elite coaches. A recent development in the study of resilience in general psychology is the introduction of two different resilience trajectories (i.e., emergent and minimal impact; Bonnano \& Diminich, 2013). Specifically, emergent resilience refers to a gradual movement toward healthy adjustment following a period of struggle with chronically aversive circumstances, whereas minimal-impact resilience refers to a stable trajectory of healthy adjustment following an isolated adversity, with recovery as a gradual return to baseline. Sport researchers might consider employing these different trajectories to better understand the exact nature of resilience by tracking relevant indicators of resilience over time, both before and after adversity (Bonanno, 2012; Bonnano \& Diminich, 2013).

Second, while this study focused on psychological resilience in world-class coaches and how they develop resilience in athletes, there is a need to investigate coaches' impact on resilience in teams (Morgan, Fletcher, \& Sarkar, 2013, 2015, 2017, 2019). Coaches play a pivotal role in influencing team resilience, particularly in relation to transformational and shared leadership, devising teamlearning strategies and cultivating a distinctive social identity (Morgan et al., 2015, 2017, 2019).

Third, to advance knowledge of developing resilience, resilience intervention studies are needed in sport (Sarkar \& Fletcher, 2016). Although there has been a burgeoning interest in resilience training interventions in the workplace (Robertson, Cooper, Sarkar, \& Curran, 2015; Sarkar \& Fletcher, 2017b), some of which have focused on coaching (Grant, Curtayne, \& Burton, 2009; SherlockStorey, Moss, \& Timson, 2013), no resilience intervention studies to date have been devised and reported in sport with coaches.

\section{Practical Implications}

In terms of the praxis of this investigation, there are a number of practical implications of the findings and themes presented. Overall, due to the ever-changing nature of psychological resilience, sport psychologists and national sport organizations should explore the need for coaches to receive education and support regarding stressors, protective factors, and enhancing resilience in athletes. In terms of stressors, sport organizations should be cognizant around the number and variety of stressors that world-class coaches experience, particularly where psychosocial education (e.g., leadership training to help with the demands of directing an organization) and external support (e.g., counseling to help with the demands of coaches' personal well-being) may be required.

In terms of protective factors, sport psychologists should identify and monitor the factors (i.e., progressive coaching, coaching support network, maintaining work/life balance, secure working environment, durable motivation, effective decision making) that an elite coach needs to exhibit resilience. Importantly, due to the interplay between coach stressors and protective factors over time, it is crucial that sport psychologists determine which particular protective factors match best with certain stressors (e.g., maintaining work/life balance to help with coaches' personal well-being), and psychologists should also intervene to attain the optimum levels of, and balance between, these factors (Sarkar \& Fletcher, 2014).

In terms of enhancing resilience in athletes, sport psychologists should work with coaches in creating environments that 
people can thrive in as both a person and a performer. Specifically, based on the findings of the current study, the environment should be characterized by individuals seeking out challenges to develop, good relationships between performers and coaches, a psychologically safe environment that encourages sensible risk taking, and learning from mistakes and failures (Fletcher \& Sarkar, 2016). Interestingly, how coaches balance this creation of a facilitative environment versus unconsciously cultivating an unrelenting environment (e.g., coaches exposing and ridiculing underperformers, a blame culture when high standards are not met, an avoidance mentality due to the consequences of making mistakes, and little care for well-being) needs to be further explored (Sarkar, 2018).

\section{Conclusion}

Although there has been burgeoning research on psychological resilience in elite athletes, to date, there has been no empirical investigation of resilience in elite coaches. Utilizing a longitudinal qualitative interview design (Hermanowicz, 2013), this study explored psychological resilience in Olympic medal-winning coaches and how they developed resilience in athletes. The findings revealed 14 higher order themes, which were categorized into the following three general dimensions: coach stressors (managing the Olympic environment, preparation for major events, coach personal well-being, directing an organization); coach protective factors (progressive coaching, coaching support network, maintaining work/life balance, secure working environment, durable motivation, effective decision making); and enhancing resilience in athletes (developing a strong coach-athlete relationship, creating a facilitative environment, developing a resilience process, athlete individual factors). This is the first empirical investigation of resilience in elite coaches, and the study provides an original and significant contribution to the resilience literature by providing a unique insight into how resilience unfolds over time in worldclass coaches, with a number of practical implications for sport psychologists and national sport organizations. Nonetheless, the body of knowledge in this area remains at a nascent stage, so the research opportunities to explore resilience in coaches are vast, and the possibilities for influencing applied/coaching practice are exciting.

\section{Author Biographies}

Dr. Mustafa Sarkar is a senior lecturer in Sport and Exercise Psychology at Nottingham Trent University. His research focuses on individual, team, and organizational resilience in elite sport and other high-performance domains (e.g., business).

Mr. Nathan Hilton is director of coaching at Nova Centurion Swimming Club, and a graduate of the MRes Sport Science program at Nottingham Trent University. His research interests broadly relate to the psychology of sports coaching.

\section{References}

American Psychological Association. (2010). Publication manual of the American Psychological Association (6th ed.). Washington, DC: Author.

Bonanno, G.A. (2004). Loss, trauma and human resilience: Have we underestimated the human capacity to thrive after extremely aversive events? American Psychologist, 59(1), 20-28. PubMed ID: 14736317 doi:10.1037/0003-066X.59.1.20
Bonanno, G.A. (2012). Uses and abuses of the resilience construct: Loss, trauma, and health-related adversities. Social Science \& Medicine, 74(5), 753-756. PubMed ID: 22300714 doi:10.1016/j.socscimed. 2011.11.022

Bonanno, G.A., \& Diminich, E.D. (2013). Annual Research Review: Positive adjustment to adversity-trajectories of minimal-impact resilience and emergent resilience. Journal of Child Psychology and Psychiatry, 54(4), 378-401. PubMed ID: 23215790 doi:10.1111/ jcpp. 12021

Braun, V., \& Clarke, V. (2006). Using thematic analysis in psychology. Qualitative Research in Psychology, 3(2), 77-101. doi:10.1191/ 1478088706qp063oa

Braun, V., \& Clarke, V. (2016). (Mis)conceptualising themes, thematic analysis, and other problems with Fugard and Potts' (2015) samplesize tool for thematic analysis. International Journal of Social Research Methodology, 19(6), 739-743. doi:10.1080/13645579. 2016.1195588

Braun, V., Clarke, V., \& Weate, P. (2016). Using thematic analysis in sport and exercise research. In B. Smith \& A. Sparkes (Eds.), Routledge handbook of qualitative research methods in sport and exercise (pp. 191-205). London, UK: Routledge.

Bryan, C., O'Shea, D., \& MacIntyre, T. (2019). Stressing the relevance of resilience: A systematic review of resilience across the domains of sport and work. International Review of Sport and Exercise Psychology, 12(1), 70-111. doi:10.1080/1750984X.2017.1381140

Charmaz, K. (1990). 'Discovering' chronic illness: using grounded theory. Social Science \& Medicine, 30(11), 1161-1172. PubMed ID: 2360052 doi:10.1016/0277-9536(90)90256-R

Clarke, V., \& Braun, V. (2014). Thematic analysis. In A.C. Michalos (Ed.), Encyclopedia of quality of life and well-being research (pp. 66266628). Dordrecht, The Netherlands: Springer.

Egeland, B., Carlson, E., \& Sroufe, L.A. (1993). Resilience as process. Development and Psychopathology, 5(4), 517-528. doi:10.1017/ S0954579400006131

Fletcher, D., \& Sarkar, M. (2012). A grounded theory of psychological resilience in Olympic champions. Psychology of Sport and Exercise, 13(5), 669-678. doi:10.1016/j.psychsport.2012.04.007

Fletcher, D, \& Sarkar, M. (2013). Psychological resilience: A review and critique of definitions, concepts, and theory. European Psychologist, 18(1), 12-23. doi:10.1027/1016-9040/a000124

Fletcher, D., \& Sarkar, M. (2016). Mental fortitude training: An evidencebased approach to developing psychological resilience for sustained success. Journal of Sport Psychology in Action, 7(3), 135-157. doi:10.1080/21520704.2016.1255496

Fletcher, D., \& Scott, M. (2010). Psychological stress in sports coaches: A review of concepts, research, and practice. Journal of Sports Sciences, 28(2), 127-137. PubMed ID: 20035490 doi:10.1080/ 02640410903406208

Frey, M. (2007). College coaches' experiences with stress: "Problem solvers have problems, too." The Sport Psychologist, 21(1), 3857. doi:10.1123/tsp.21.1.38

Galli, N., \& Gonzalez, S.P. (2015). Psychological resilience in sport: A review of the literature and implications for research and practice. International Journal of Sport and Exercise Psychology, 13(3), 243257. doi:10.1080/1612197X.2014.946947

Galli, N., \& Vealey, R.S. (2008). "Bouncing back" from adversity: Athletes' experiences of resilience. The Sport Psychologist, 22, 316-335.

Glaser, B.G., \& Strauss, A.L. (1967). The discovery of grounded theory: Strategies for qualitative research. New York, NY: Aldine de Gruyter.

Grant, A.M., Curtayne, L., \& Burton, G. (2009). Executive coaching enhances goal attainment, resilience and workplace well-being: 
A randomised controlled study. The Journal of Positive Psychology, 4(5), 396-407. doi:10.1080/17439760902992456

Hermanowicz, J.C. (2013). The longitudinal qualitative interview. Qualitative Sociology, 36, 189-208. doi:10.1007/s11133-013-9247-7

Hodge, K., Henry, G., \& Smith, W. (2014). A case study of excellence in elite sport: Motivational climate in a world champion team. The Sport Psychologist, 28(1), 60-74. doi:10.1123/tsp.2013-0037

Lara-Bercial, S., \& Mallett, C.J. (2016). The practices and developmental pathways of professional and Olympic serial winning coaches. International Sport Coaching Journal, 3(3), 221-239. doi:10. 1123/iscj.2016-0083

Luthar, S.S., Cicchetti, D., \& Becker, B. (2000). The construct of resilience: A critical evaluation and guidelines for future work. Child Development, 71(3), 543-562. PubMed ID: 10953923 doi:10.1111/ 1467-8624.00164

Mallett, C.J., \& Coulter, T.J. (2016). The anatomy of a successful Olympic coach: Actor, agent, and author. International Sport Coaching Journal, 3(2), 113-127. doi:10.1123/iscj.2015-0069

Mallett, C.J., \& Lara-Bercial, S. (2016). Serial winning coaches: People, vision, and environment. In M. Raab, P. Wylleman, R. Seiler, A.M. Elbe, \& G. Hatzigeorgiadis (Eds.), Sport and exercise psychology research: Theory to practice (pp. 289-322). Amsterdam, The Netherlands: Elsevier.

Martin-Krumm, C.P., Sarrazin, P.G., Peterson, C., \& Famose, J. (2003). Explanatory style and resilience after sports failure. Personality and Individual Differences, 35(7), 1685-1695. doi:10.1016/S0191-8869 (02)00390-2

Morgan, P.B.C., Fletcher, D., \& Sarkar, M. (2013). Defining and characterizing team resilience in elite sport. Psychology of Sport and Exercise, 14(4), 549-559. doi:10.1016/j.psychsport.2013.01.004

Morgan, P.B.C., Fletcher, D., \& Sarkar, M. (2015). Understanding team resilience in the world's best athletes: A case study of a rugby union world cup winning team. Psychology of Sport and Exercise, 16(Part 1), 91-100. doi:10.1016/j.psychsport.2014.08.007

Morgan, P.B.C., Fletcher, D., \& Sarkar, M. (2017). Recent developments in team resilience research in elite sport. Current Opinion in Psychology, 16, 159-164. PubMed ID: 28813342 doi:10.1016/j.copsyc. 2017.05.013

Morgan, P.B.C., Fletcher, D., \& Sarkar, M. (2019). Developing team resilience: A season-long study of psychosocial enablers and strategies in a high-level sports team. Psychology of Sport and Exercise, 45, 101543. doi:10.1016/j.psychsport.2019.101543

Mummery, W.K., Schofield, G., \& Perry, C. (2004). Bouncing back: The role of coping style, social support, and self-concept in resilience of sport performance. Athletic Insight, 6, 1-18.

Olusoga, P., Butt, J., Hays, K., \& Maynard, I. (2009). Stress in elite sports coaching: Identifying stressors. Journal of Applied Sport Psychology, 21(4), 442-459. doi:10.1080/10413200903222921

Olusoga, P., Butt, J., Maynard, I., \& Hays, K. (2010). Stress and coping: A study of world class coaches. Journal of Applied Sport Psychology, 22(3), 274-293. doi:10.1080/10413201003760968

Olusoga, P., Maynard, I., Hays, K., \& Butt, J. (2012). Coaching under pressure: A study of Olympic coaches. Journal of Sports Sciences, 30(3), 229-239. PubMed ID: 22168369 doi:10.1080/02640414.2011. 639384

Patton, M.Q. (1990). Qualitative evaluation and research methods. Thousand Oaks, CA: Sage.

Patton, M.Q. (2002). Qualitative research and evaluation methods (3rd ed.). Thousand Oaks, CA: Sage.
Richardson, G.E. (2002). The meta-theory of resilience and resiliency. Journal of Clinical Psychology, 58(3), 307-321. PubMed ID: 11836712 doi: $10.1002 /$ jclp. 10020

Richardson, G.E., Neiger, B.L., Jensen, S., \& Kumpfer, K.L. (1990). The resiliency model. Health Education, 21(6), 33-39. doi:10.1080/ 00970050.1990.10614589

Robertson, I.T., Cooper, C.L., Sarkar, M., \& Curran, T. (2015). Resilience training in the workplace from 2003 to 2014: A systematic review. Journal of Occupational and Organizational Psychology, 88(3), 533-562. doi:10.1111/joop.12120

Roulston, K. (2010). Considering quality in qualitative interviewing. Qualitative Research, 10(2), 199-228. doi:10.1177/14687941093 56739

Saldana, J. (2003). Longitudinal qualitative research: Analyzing change through time. Walnut Creek, CA: Altamira.

Sarkar, M. (2018). Developing resilience in elite sport: The role of the environment. The Sport and Exercise Scientist,55, 20-21.

Sarkar, M., \& Fletcher, D. (2014). Psychological resilience in sport performers: A review of stressors and protective factors. Journal of Sports Sciences, 32(15), 1419-1434. PubMed ID: 24716648 doi:10.1080/02640414.2014.901551

Sarkar, M., \& Fletcher, D. (2016). Developing resilience through coaching. In R. Thelwell, C. Harwood, \& I. Greenlees (Eds.), The psychology of sports coaching: Research and practice (pp. 235-248). London, UK: Routledge.

Sarkar, M., \& Fletcher, D. (2017a). Adversity-related experiences are essential for Olympic success: Additional evidence and considerations. Progress in Brain Research, 232, 159-165. doi:10.1016/bs. pbr.2016.11.009

Sarkar, M., \& Fletcher, D. (2017b). How resilience training can enhance wellbeing and performance. In M.F. Crane (Ed.), Managing for resilience: A practical guide for employee wellbeing and organizational performance (pp. 227-237). London: Routledge.

Sarkar, M., Fletcher, D., \& Brown, D.J. (2015). What doesn't kill me . . adversity-related experiences are vital in the development of superior Olympic performance. Journal of Science and Medicine in Sport, 18(4), 475-479. PubMed ID: 25035123 doi:10.1016/j.jsams.2014. 06.010

Seligman, M.E., Nolen-Hoeksema, S., Thornton, N., \& Thornton, K.M. (1990). Explanatory style as a mechanism of disappointing athletic performance. Psychological Science, 1(2), 143-146. doi:10.1111/j. 1467-9280.1990.tb00084.x

Sherlock-Storey, M., Moss, M., \& Timson, S. (2013). Brief coaching for resilience during organisational change-An exploratory study. The Coaching Psychologist, 9, 19-26.

Silverman, D. (2006). Interpreting qualitative data: Methods for analyzing talk, text and interaction (3rd ed.). London, UK: Sage.

Simonton, D.K. (1999). Significant samples: The psychological study of eminent individuals. Psychological Methods, 4(4), 425-451. doi:10. 1037/1082-989X.4.4.425

Smith, B., \& McGannon, K.R. (2018). Developing rigor in qualitative research: Problems and opportunities within sport and exercise psychology. International Review of Sport and Exercise Psychology, 11(1), 101-121. doi:10.1080/1750984X.2017.1317357

Sparkes, A.C., \& Smith, B. (2009). Judging the quality of qualitative inquiry: Criteriology and relativism in action. Psychology of Sport and Exercise, 10(5), 491-497. doi:10.1016/j.psychsport.2009.02.006

Strauss, A., \& Corbin, J. (1994). Grounded theory methodology: An overview. In N. Denzin \& Y. Lincoln (Eds.), Handbook of qualitative research (pp. 262-272). London, UK: Sage. 
Thelwell, R., Weston, N.J., \& Greenlees, I. (2010). Coping with stressors in elite sport: A coach perspective. European Journal of Sport Science, 10(4), 243-253. doi:10.1080/17461390903353390

Thelwell, R.C., Weston, N.J., Greenlees, I.A., \& Hutchings, N.V. (2008a). A qualitative exploration of psychological skills use in coaches. The Sport Psychologist, 22(1), 38-53. doi:10.1123/tsp.22.1.38

Thelwell, R.C., Weston, N.J., Greenlees, I.A., \& Hutchings, N.V. (2008b). Stressors in elite sport: A coach perspective. Journal of Sports Sciences, 26(9), 905-918. doi:10.1080/02640410801885933
Tracy, S.J. (2010). Qualitative quality: Eight "big-tent" criteria for excellent qualitative research. Qualitative Inquiry, 16(10), 837-851. doi:10.1177/1077800410383121

Ungar, M. (2003). Qualitative contributions to resilience research. Qualitative Social Work, 2(1), 85-102. doi:10.1177/1473325003002001123

White, R.L., \& Bennie, A. (2015). Resilience in youth sport: A qualitative investigation of gymnastics coach and athlete perceptions. International Journal of Sports Science \& Coaching, 10(2-3), 379-394. doi:10.1260/1747-9541.10.2-3.379 